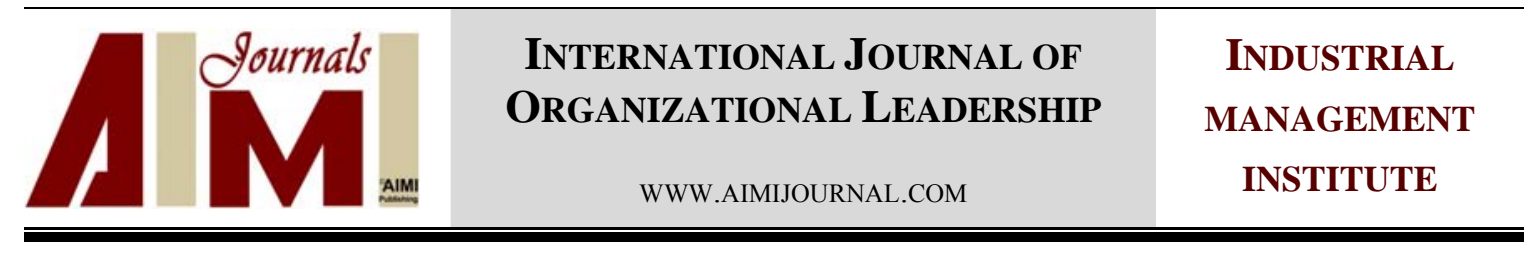

\title{
The effect of in-service entrepreneurship training on mass media managers' entrepreneurship: A case study of IRIB
}

\author{
Hassan Motaharrad*1 ${ }^{1}$, Hamid Reza Arasteh ${ }^{2}$ Parivash Jafari $^{3}$ \\ ${ }^{1,3}$ Department of Educational Administration, Science and Research Branch, \\ Islamic Azad University, Tehran, Iran \\ ${ }^{2}$ Department of Educational Administration, Kharazmi University, Iran
}

\begin{abstract}
Keywords:

Corporate Entrepreneurship, Creativity, Risk-taking, Perseverance, Competitive Spirit, Entrepreneurship Training

Correspondence:

motaharrad@yahoo.com

This study investigates the impact of in-service entrepreneurship training on the improvement of mass media managers' entrepreneurship in Islamic Republic of Iran Broadcasting (IRIB), Tehran, Iran. Features of corporate entrepreneurship were regarded as four dimensions of creativity and innovation, risk-taking, perseverance, and competitive spirit. Also, we examined the effect of entrepreneurship training on corporate entrepreneurship. To collect the data, we developed a questionnaire. Forty four production managers of IRIB volunteered to fill in the questionnaire. However, 4 persons were excluded from the group due to incomplete completion of the questionnaire and treatment which made the participants 40 people. The participants were randomly assigned to two participating groups. To test the hypotheses, variance and multi-covariance tests were applied. The analysis of the data obtained showed that the entrepreneurship training has significant effect on creativity, risk-taking, perseverance, and competitive spirit.
\end{abstract}

(C)AIMI Journals

\section{Introduction}

Nowadays, societies are encountered with widespread international threats and changes.

These social and economic changes of this age are the results of scientific and technological progress which, in turn, have led to new perspectives (Mashayekhi, Tajabadi, \& Moradinejad, 
2008). Organizations in order to survive and create values have to adapt themselves to the situations. Therefore, to achieve this goal, organizations turn to innovation and creation and generally try to go for entrepreneurship either in product and services or process. The survival of the organizations is highly dependent upon the existence of active corporate entrepreneurship. According to Islam, an entrepreneur is the one who depends on himself and with faith in God would try hard so as to use all his physical, mental, and financial potentials as well as his expertise in the right way to his advantage (Khonifar, 2006). In fact, such people are the motors of organizations and insert energy to them in face of difficulties. Corporate entrepreneurship amends the traditional management views so as to bring about competitions amongst organizations which results in fulfilling the endless needs of the customers. As a matter of fact, corporate entrepreneurship is a concept in close relation with entrepreneuring in one organization (Pardakhtchi \& Shafizadeh, 2006).

Given the role and significance of entrepreneurship in the economic development of a vast number of countries and due to the critical economic problems which Iran is encountered and accordingly it is reaching out to various sources, we need to develop and illustrate the concept of entrepreneurship and also support it and most importantly recruit educated persons (Hamid Aqaei, 1998).

\section{Literature Review}

This very concept always existed from the dawn of creation and is always with human being and is the basis of all human changes and advances. The entrepreneurial literature reveals that this concept is involved in all human being activities (Hamid Aqaei, 1998). The terminology entrepreneurship is rooted in a French word Entreprendre which means broker and mediator or an English expression to undertake with the meaning of to commit. Entrepreneurship includes a learning process and is to be able to overcome difficulties and problems and also learn from them (Deakins \& Freel, 1998).

According to the Webster dictionary, an entrepreneur is the one who undertakes, organizes, and manages the risks of an economic activity. Entrepreneurship long before being used with today's concept was invented by the French. At the beginning of the sixteenth century those who were leading martial missions were called entrepreneurs. Also, this terminology was used for other risks with certain limitations from that time. As of 1700, the French used to call the governmental contractors who were in charge of making roads, bridges, and ports entrepreneurs repeatedly. Entrepreneur unlike its appearance does not 
mean creation of jobs. This concept is known as creation of jobs even amongst educated people. While creation of jobs might be one of the results of entrepreneurship which so far no good translation for this concept was being found and some people translate it as value creation (Ahmadpoor Dariani, 2004).

\section{Types of Entrepreneurship}

Entrepreneurial literature shows that entrepreneurship is shaped in three forms. Firstly, it is shown in the form of independent people detached from any organizations (individual entrepreneurship-independent entrepreneurship); secondly, it is presented in the form of organization staff (organizational entrepreneurs- intrapreneurs); and finally, it is displayed in the form of the organization (entrepreneurial organization-corporate entrepreneurship) (Hamid Aqaei, 1998).

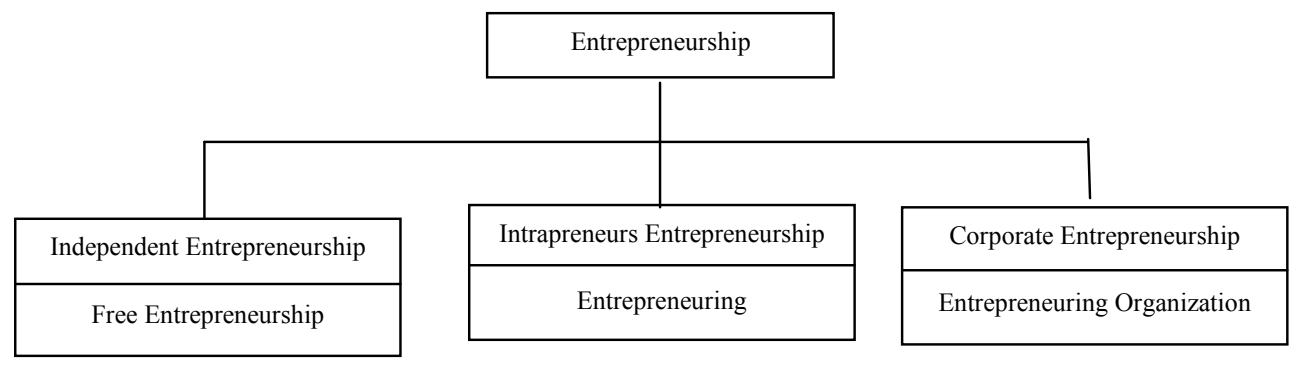

Figure 1.Types of entrepreneurship

Furthermore, it should be mentioned that effective entrepreneurship falls into three categories, including structural dimension, behavioral dimension, and environmental dimension (Moqimi, 2009).

\section{The Behavioral Dimension of Corporate Entrepreneurship}

Entrepreneurial recruitment through considering different experiences provides a vision for people in order to take advantage of various opportunities. The key word in entrepreneurial recruitment is experience. In entrepreneurial recruitment, we deal with knowledge and awareness pertinent to entrepreneurship to promote jobs and also provide skills so that the new job develops (Pardakhtchi \& Shafizadeh, 2006).

Drucker (1985) asserted that entrepreneurship is not magical, not mysterious; it can be like other majors trained. He refers to organized attempts which are implemented to certain 
personnel through one organization to ease the learning processes pertaining to the job. Corporate entrepreneurship contains different dimensions such as creativity and innovation, risk-taking, perseverance, and aggressive competition (Agarwal, Audretsch, \& Sarkar, 2010). Figure 1 presents effective factors on corporate entrepreneurship adapted from Moqimi (2004).

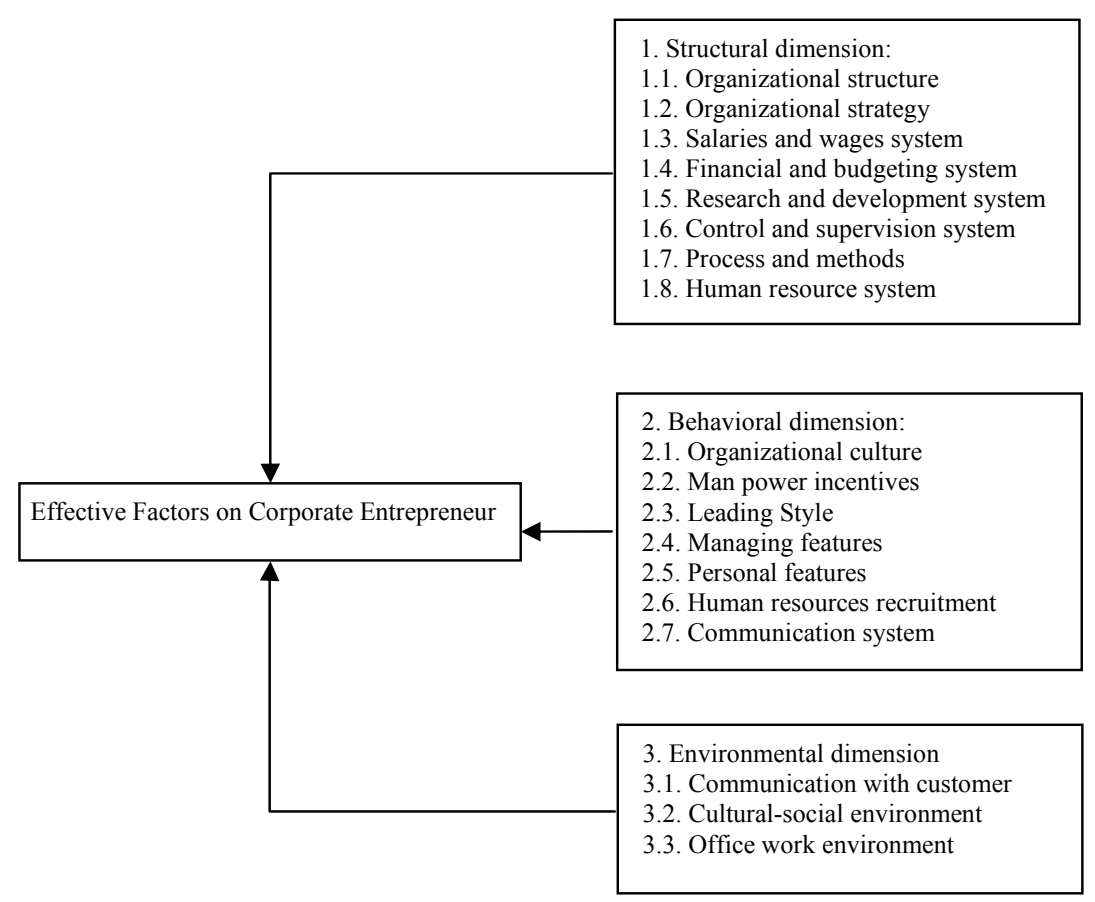

Figure 2. The model of effective factors on corporate entrepreneurship (Adopted from Moqimi, 2004)

\section{Contributing Factors in Entrepreneurship}

It is important to mention that one of the wonderful features of human mind is creation and innovation (Seif, 2009). Creative thoughts are internalized in human beings by nature. However, their materialization requires development. Developing creative faculty and use of it is necessary for the survival of human being. Creativity is the main weapon of human being with which he can ease into daily mental pressures imposed on him (Hosseini, 2006). In fact, innovation aims to implement the thoughts and viewpoint resulting from creativity such as presenting products, services, and new ways to do so. Interestingly enough, innovation might focus on using one old technique to solve a new issue in a way that formerly it was not implemented like that. 
Nowadays, creativity and its propagation and recruitment are amongst the factors which an entrepreneur or a successful organization has in mind. Creativity is equal to the ability to combine ideas in an extraordinary way to create new relationship amongst various ideas. Precisely speaking, creativity emphasizes ability not activity (Hezarjaribi, 2005). For an individual who might propose a new idea, there is no necessity in order to change it to a fact. Creativity is a prerequisite to innovation and ideas in turn bear no values unless they turn to a new product, service, or product. Creativity is a spirit which is inserted into entrepreneurship and innovation is the process of entrepreneurship. Both creativity and innovation are indispensible components of entrepreneurship. According to Drucker (1985), the existence of innovation in entrepreneurship is necessary to the extent that entrepreneurship without innovation cannot exist and creativity without innovation is not useful. In sum, innovation is the most important factor in entrepreneurship (Holt \& David, 2002).

Taking risk either financially, mentally, or socially is a part of entrepreneurship. Of course, the entrepreneur does not take risk but measures the possible risk and then does not stop trying to get the favored result. Their measurements and predictions mostly prevent unnecessary risks. There is a belief that those who have higher sense of achievement usually take moderate risks. Also, successful entrepreneurs avoid risk-taking less than managers (Dehqanpoor, 2002).

In addition, risk taking is an individual's tendency to encounter risks when one is in the context. Risk taking is accepting and welcoming estimated dangers in business. This feature is the one which exists in most entrepreneurs (Hamid Aqaei, 1998).

Perseverance refers to one's seriousness and insistence to finish a work after initiation (Masoudnia, 2007). Successful people believe in perseverance and efforts. They believe that systematic insistence and resistance to do a job are always accompanied by success and no great success comes without non-stop perseverance and gravity. If we take a look at successful people in different fields we would notice that they were not necessarily better, more intelligent, faster, or stronger; in fact, they were more persistent and perseverant and instead of depending on their intelligence quotient (IQ), they strengthened their emotional quotient (EQ).

Competitive spirit refers to the intensity of company efforts so as to move forward and weaken the competitors' industries. This could be a deliberate action in comparison with reaction. Companies which have high competitive spirit regard their competitors as their enemies who need to be controlled (Agarwal, Audretsch, \& Sarkar, 2010). 


\section{Statement of the Problem}

Corporate entrepreneurship in terms of the development of merits and opportunities inside the organization through the combination of different sources is a new viewpoint. There is a belief that entrepreneurial behavior is a widespread need and necessary for all organizations namely governmental, private, and volunteer with whatever size, i.e., average or small. In certain countries, the restructuring of governmental organizations was done so as to promote the efficiency of these organizations through eliminating organizational impediments and in some other countries this was done via privatization.

Experts believe that organizational reforms and privatization could not succeed without entrepreneurship. The main hypothesis here is that organizations all over the world are required to spread entrepreneurial behaviors so that they survive (Sardari, 2004). Entrepreneurial recruitment is a systematic process which is purposeful and people with potential would be trained to be entrepreneurs. Entrepreneurial recruitment is certain activities through which the required knowledge and information in terms of entrepreneurship are passed down and as a result the skills and abilities as well as the potentials of the people who were not entrepreneurs would increase and improve.

\section{Framework of the Study}

To do the research, the researcher needed a model which is presented below and confirmed by the related experts.

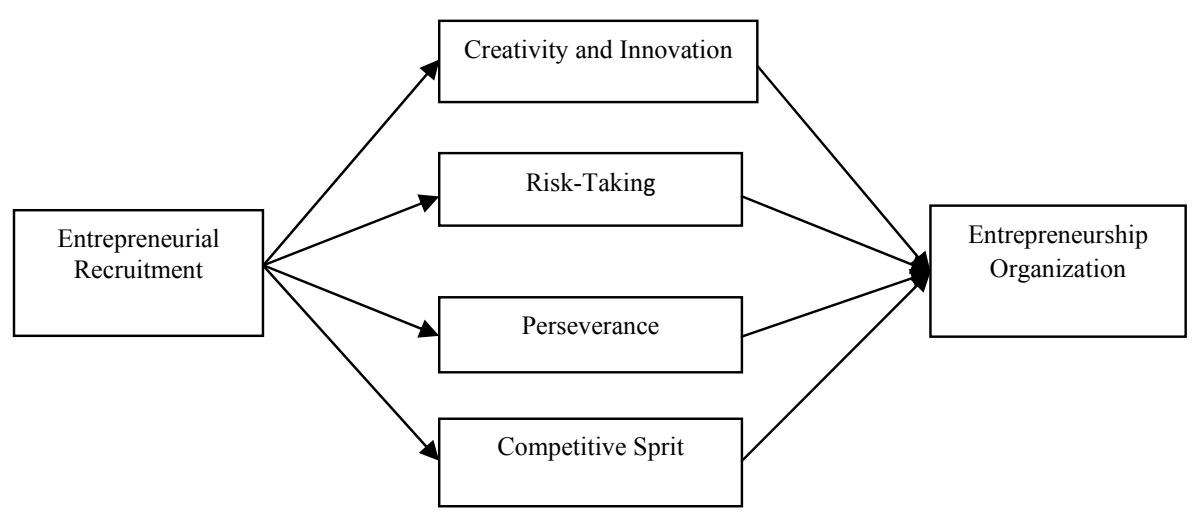

Figure 3.The related model

Lack of attention to entrepreneurial recruitment or entrepreneurial criteria in training especially those which are supposed to cause changes in the management methods or in the 
work environment as a result of the recruitment become the managers and educational authorities' obsession. Based on the formal and informal meetings held with managers of IRIB, the researcher came to know that lack of variety in the management affairs and also after interviewing the educational authorities, it was clarified that amongst the factors which caused problems for the organizations, the following ones, namely managers' low creativity, conservation in decision making, low competitive spirit, and low perseverance were considered to be crucial factors.

\section{Research Questions}

The following questions guided this study:

- Does the entrepreneurial recruitment have any effect on managers' corporate entrepreneurship of IRIB?

- If so, to what extent this recruitment increase creativity, innovation, risk-taking, perseverance, and competitive spirit of IRIB managers?

\section{Research Hypotheses}

The main hypothesis of this study was postulated as:

Entrepreneurial recruitment for IRIB managers would promote corporate entrepreneurship.

Other hypotheses:

- Entrepreneurial recruitment for IRIB managers would increase their creativity and innovation.

- Entrepreneurial recruitment for IRIB managers would increase their risk-taking.

- Entrepreneurial recruitment for IRIB managers would increase their perseverance.

- Entrepreneurial recruitment for IRIB managers would increase their competitive spirit.

\section{Method}

This study probes into the effect of in-service entrepreneurship training on the improvement of mass media managers' entrepreneurship. The research design is quasi-experimental. Pretest and post-test were given to students in order to test the hypotheses. Groups were selected from IRIB and the participants were randomly assigned to two participating groups. Pre-test was administered to both experimental and control groups. The independent variable (corporate entrepreneurship recruitment) was implemented on the experimental group and the result in the dependent variable (corporate entrepreneurship) was tested. However, measures 
which indicate the interference of dependent variable on control group were not taken. In addition, after recruitment, the final post-test was administered to both groups and the results were analyzed.

\section{Participants}

The participants of the study were IRIB managers. Forty four production managers volunteered to fill in the questionnaire and they were randomly divided into two groups. Four people were excluded from the group due to incomplete completion of the questionnaire and treatment period. For data collection, corporate entrepreneurship questionnaire based on pretest and post-test was used. The related questionnaire was developed by the researcher adapting from Agarwal, Audretsch, and Sarkar (2010). It assessed four variables of creativity and innovation, risk-taking, perseverance, and competitive spirit. The validity of the questionnaire was checked by Cronbach's alpha coefficient.

\section{Results}

Given the topic, purpose, and hypotheses of the research, the researcher used descriptive statistics so as to analyze and interpret the data and to investigate gender, marital status, educational level, and experience. Also, to test the hypothesis, the researcher used inferential statistics. Also, two tests of Mancova and t-test were used and Manova multi-variance interpretation to investigate innovation, risk-taking, perseverance, and aggressive competition between two groups were applied.

The mean of experimental and control groups' innovation was not different in pre-test $(7.79,7.70)$. However, the difference in the mean of the post-test is obvious. $(14.50,9.25)$. Therefore, it can be argued that entrepreneurial recruitment for IRIB managers would enhance their creativity in the first place as well as innovation of experimental group in comparison with control group in the post test. The risk-taking means of experimental and control groups in the pre-test was not different $(10.95,10.80)$ but in the risk-taking mean of post-test there existed difference $(14.80,11.60)$. Therefore, it can be concluded that entrepreneurial recruitment for IRIB managers increased the risk-taking of experimental group compared to that of the control group in post-test.

The perseverance mean of experimental and control groups in the pre-test was not different $(8.10,8.10)$; however, the mean in the post-test was different $(14.35,9.30)$. Therefore, entrepreneurial recruitment for IRIB managers would heighten the perseverance of 
the experimental group. The same goes with competitive spirit which no difference in the pre-test existed $(7.80,7.85)$. So, this was significant in the post-test $(14.25,8.80)$. Therefore, entrepreneurial recruitment would increase the competitive spirit of the experimental group.

As Table 1 presents, level of error for four variables of creativity, risk-taking, perseverance, and competitive spirit was not significant and this reveals that the error variance among participants was not different.

Table 1

Leven's Test to Assess the Equality of the Variances in Corporate Entrepreneurship Variables

\begin{tabular}{ccccc}
\hline Variable & F & Df1 & Df2 & Significance Level \\
\hline Creativity & 1.68 & 1 & 38 & 0.20 \\
Risk-Taking & 2.63 & 1 & 38 & 11 \\
Perseverance & 15.68 & 1 & 38 & 0.23 \\
Competitive Sprit & 1 & 1 & 38 & 0.11 \\
\hline
\end{tabular}

Table 2

Information Pertinent to Validity Index of Corporate Entrepreneurship

\begin{tabular}{lccccc}
\hline \multicolumn{1}{c}{ Effect } & Value & F & Df & Error Df & Significance level \\
\hline Pillai's Trace & 0.66 & 17.04 & 4 & 35 & 0.000 \\
Wilks Lamba & 0.33 & 17.04 & 4 & 35 & 0.000 \\
Hotelling Effect & 1.94 & 17.04 & 4 & 35 & 0.000 \\
& 1.94 & 17.04 & 4 & 35 & 0.000 \\
\hline
\end{tabular}

As it is presented in Table 2, the Wilks lambda was 0.00 which was significant in $p \leq 0.01$ level. The difference was significant in terms of creativity, risk-taking, perseverance, and competitive spirit which resulted from entrepreneurial recruitment. In order to recognize which corporate entrepreneurship variables between two groups were different, Multi-Variate test was run. Table 3 summarizes the results of the analysis run.

Table 3

Analysis of Multi-Variate Test of Creativity, Risk-Taking, perseverance, and Competitive Spirit between Two

\begin{tabular}{|c|c|c|c|c|c|c|c|}
\hline Resource & Sale & $\begin{array}{l}\text { Sum of } \\
\text { squares }\end{array}$ & $\overline{\mathrm{Df}}$ & Mean square & $\mathrm{F}$ & $\begin{array}{c}\text { Significance } \\
\text { level }\end{array}$ & Effect degree \\
\hline \multirow{4}{*}{ Model } & Creativity & 275.62 & 1 & 275.62 & 43.61 & 0.00 & 0.53 \\
\hline & Risk-taking & 93.02 & 1 & 93.02 & 26.43 & 0.00 & 0.41 \\
\hline & Perseverance & 255.02 & 1 & 255.02 & 28.76 & 0.00 & 0.43 \\
\hline & Competitive spirit & 297 & 1 & 297.02 & 45.55 & 0.00 & 0.54 \\
\hline \multirow{4}{*}{ Intercept } & Creativity & 697.22 & 1 & 697.22 & 110.32 & 0.00 & 0.74 \\
\hline & Risk-taking & 216.22 & 1 & 216.22 & 61.43 & 0.00 & 0.61 \\
\hline & Perseverance & 555.02 & 1 & 555.02 & 62.59 & 0.00 & 0.62 \\
\hline & Competitive spirit & 540.22 & 1 & 540.22 & 82.86 & 0.00 & 0.68 \\
\hline \multirow{4}{*}{ Groups } & Creativity & 275.62 & 1 & 275.62 & 43.61 & 0.00 & 0.53 \\
\hline & Risk-taking & 93.02 & 1 & 93.02 & 26.43 & 0.00 & 0.41 \\
\hline & Perseverance & 255.02 & 1 & 255.02 & 28.76 & 0.00 & 0.43 \\
\hline & Competitive spirit & 297.02 & 1 & 297.02 & 45.55 & 0.00 & 0.54 \\
\hline
\end{tabular}


Table 3 exhibits that the hypothesis that entrepreneurial recruitment has significant impact on creativity, risk-taking, perseverance, and competitive spirit was confirmed. In fact, experimental group entailed higher entrepreneurship after recruitment. Entrepreneurial recruitment for IRIB managers enhanced their innovation. As Table 3 shows, with regard to creativity variable $p$ and $\mathrm{F}$ were as follows: $p \leq 0.01, \mathrm{~F}=110.32$. Therefore, the research hypothesis indicting the effectiveness of innovation was confirmed.

Entrepreneurial recruitment for IRIB managers increased their risk-taking. According to Table 3, the research hypothesis concerning the effect of recruitment and risk-taking was confirmed. That is, risk-taking recruitment had an effect on experimental group in the posttest period.

Entrepreneurial recruitment for IRIB managers increased their perseverance. Based on Table 3, the hypothesis regarding the effect of recruitment on perseverance was confirmed as well. That is, the role of perseverance training in the success of experimental group in the post test was effective.

Entrepreneurial recruitment prompted the competitive spirit of the IRIB managers. As Table 3 reveals, the hypothesis regarding the effect of competition role was confirmed. That is, the effect of training competition in success of experimental group in the post-test part was significant.

\section{Discussion}

The findings of the study indicate that the entrepreneurial recruitment had significant impact on innovation, risk-taking, perseverance, and competitive spirit. The findings of this study is in line with the previous studies but reveal that the entrepreneurial recruitment increases innovation, risk-taking, perseverance, and competitive spirit of the people which demonstrates positive effect on competition with other organizations.

Corporate entrepreneurship is a process in which the products or innovative processes via entrepreneurial culture-building in one pre-established organization are after achieving innovative results (Hamid Aqaei, 1998). This process requires an entrepreneurial act or an agent. An entrepreneurial act refers to the implementation of an idea, process, product, service, or a new business. An entrepreneurial agent refers to an individual or a group who are in charge of materialization of that entrepreneurial act. Entrepreneurial process includes behavioral and attitudinal components. 
Given the fact that the first hypothesis, indicating the effect of entrepreneurial recruitment on innovation as one of the variables of corporate entrepreneurship was confirmed, it can be argued that creativity and then innovation are regarded as the essence of entrepreneurship and the key to the success and survival of organizations. Organizations are preparing themselves so as to catch up with the quick changes of management in the age known as speed age, knowledge age, innovation and creativity age, and post-industrial age.

Nowadays, creativity and innovation are the necessities for survival and promotion of the position of organizations. At this critical juncture, the challenge to rank the best in the realm of science and technology already has begun. Also, organizations are preparing themselves to encounter with this coming change and are in search of innovative ways. Nowadays, the pace of changes is far-fetched in a way that creativity and innovation are considered the main factor in the survival of any organizations and innovation is regarded as the competitive advantage for them. In this situation, those organizations are successful which have more creative human resources and most importantly managers who create innovative atmosphere. Main motivation for creativity and innovation is individual's tendency to move towards development of his or her best potentials. Training creativity techniques would prompt entrepreneurship. So, people are inspired to reach the highest level of self-actualization and make the best use of their abilities after training which is considered as a type of self-training. Generally, creativity techniques would create Newtonian viewpoint, i.e., every day thousands of apples fall from trees but Newton innovates. So, this training causes such viewpoints.

According to the second hypothesis, psychologists regard economic growth as the product of human behaviors such as decision-making, thoughts, and acts. Also, they believe that incentives and intuitions are effective on economic growth. Entrepreneurial impressions are not just those of economic ones but they also include impressions which lead to social and cultural changes as well. Palmer (1987) defined entrepreneurs as creative and self-confident people. He believes that wealth is created by brave people. The need for progress is the main incentive for the economic development of countries and would turn an individual to an entrepreneur. Besides, the need for progress and entrepreneurship would cause economic growth in the production units. Risk taking can be controlled by personal attempts. Two factors are involved in risk taking, including entrepreneur's level of understanding of risk at the beginning of each risky activity and considering the odds of failure in case that activity fails. The risks entrepreneurs take in running their business differ. For instance, by investing their own money they accept the financial risks and with quitting their jobs they accept the 
occupational risks. Entrepreneurs are people who take calculated risks and are not necessarily after risky activities; however, they are willing to accept certain normal risks at the initiating stage of running business and to achieve this they endanger their money, safety, popularity, and their positions. Also, since the phenomena such as interest rate, success, and competitions in the realm of entrepreneurial activities are not clear; therefore, the person is to stand these risks, and otherwise, he would not dare to start new businesses. According to the results of this study the experimental group turned out to be more tolerant in the face of high risks and it goes back to the training they went through. Besides, previous studies confirmed the fact that entrepreneurs were up to take higher risks.

According to the third hypothesis, it can be argued that perseverance and efforts are important features of entrepreneurs. They know no change comes out of sitting in one place and not to make an attempt and they are of belief that willpower can overcome the thought. Determination and willpower are main factors to succeed. Resistance and insistence are determining factors on the way towards success. In addition, determination and efforts are effective for innovation on entrepreneurial activities and this, in turn, would increase economic and business performance of the managers.

Considering the forth hypothesis which indicates the effect of entrepreneurship on competitive spirit, it can be argued that entrepreneurial recruitment can increase this spirit with encouraging them to stand risks and changes and to work in dynamic atmosphere since this spirit is regarded as one feature of entrepreneurs and it is related to the entrepreneurial behavior dimension. Besides, it does not focus on the behavior which can be changed by recruitment.

\section{Conclusion}

In brief, it can be suggested that creativity recruitment to achieve corporate entrepreneurship must be considered as an important factor. Also, it is recommended to train risk-taking tolerance to entrepreneurs. Moreover, attention to perseverance in strategy making is regarded as a significant factor. This requires a lot of attempts to be materialized on the part of IRIB managers. Further, the competitive spirit should be attached primary importance since IRIB is competing with powerful competitors such as satellite networks. Not following this competition would lead to repetitive and boring programs and as a result replacing satellite TV in the society. 


\section{References}

Agarwal, R., Audretsch, D., \& Sarkar, M. (2010). Knowledge spillovers and strategic entrepreneurship. Strategic Entrepreneurship Journal, 4, 271-283.

Ahmadpour Dariani, M. (2004). Entrepreneurship: Definitions, theories, models (5 $5^{\text {th }}$ ed.). Tehran: Pardis.

Deakins, D., \& Freel, M. (1998). Entrepreneurial learning and the growth process in SMEs. The Learning Organization, 5(3), 144-155.

Dehqanpoor, A. (2002). Entrepreneurship and entrepreneurs. Industry Quarterly, 3, 3-8.

Drucker, P. F. (1985). Innovation and entrepreneurship: Practice and principles. New York: Harper \& Row.

Entrepreneur. (n.d.). In Merriam-Webster's online dictionary $\quad\left(11^{\text {th }}\right.$ ed.). Retrieved from http://www.mw.com/dictionary/entrepreneur

Feizi, K., \& Moqadasi, A. (2003). Research on concepts and training courses of entrepreneurship. Industrial Management Quarterly, 3, 126-137.

Flippo, E. B., \& Munsinger, G. M. (1975). Management ( $3^{r d}$ ed.). Boston: Allyn \& Bacon, Inc.

Hamid Aqaei, J. (1998). From entrepreneurship to human resource creation. Tadbir Magazine, 87, 24-29.

Hezarjaribi, J. (2005). Investigating the role of entrepreneur in creation of economical opportunities. Journal of Economic Research, 5(3), 237-267.

Holt, H., \& David, H. (2002). Entrepreneurship: New venture creation. New Delhi: Prentice Hall.

Hosseini, A. (2006). Creativity growth model and its efficiency in teaching skills. Quarterly Journal of Educational Innovations, 5(15), 177-201.

Khonifar, H. (2006). Entrepreneurship in the value system. Tehran: Ekram.

Mashayekhi, K., Tajabadi, R., Moradinejad, A. (2008). The students' motivation, creativity, entrepreneurship, and the role of applied science teachers to motivate entrepreneurship among students. Proceedings of National conference on Entrepreneurship Development Training Applied Science in Agriculture, Iran.

Masoudnia, E. (2007). The investigation of validity of personality paradigms in entrepreneurship prediction and study. Journal of Daneshvar Raftar, 14(2), 23-54.

Moqimi, S. M. (2009). The effective factors on organizational entrepreneurship in social and cultural services of state sector in Iran. Journal of Management Culture, 2(7), 27-78.

Palmer, M. (1987). The application of psychological testing to entrepreneurial Potential. Entrepreneurial and Ventur Management. N. J.: Practice Hall.

Pardakhtchi, M., \& Shafizadeh, H. (2006). Introduction to organizational entrepreneurship (1 ${ }^{\text {st }}$ ed.). Tehran: Arsbaran.

Sardari, A., (2004). The investigation of the relationship between incorporate culture with job satisfaction in academic centers associated to higher education in Tehran. Journal of Danehvar Raftar, 11(5), 55-65.

Seif, A. (2009). Modern educational psychology: Learning and teaching psychology. Tehran: Agah. 